Review Article

\title{
Foreseeable challenges in developing telesurgery for low income and middle income countries
}

\section{Vethunan Tamalvanan*}

Department of Surgery, Hospital Pakar Sultanah Fatimah Muar, Malaysia

Received: 21 July 2021

Accepted: 25 August 2021

\section{*Correspondence:}

Dr. Vethunan Tamalvanan,

E-mail: vethunan@gmail.com

Copyright: (C) the author(s), publisher and licensee Medip Academy. This is an open-access article distributed under the terms of the Creative Commons Attribution Non-Commercial License, which permits unrestricted non-commercial use, distribution, and reproduction in any medium, provided the original work is properly cited.

\begin{abstract}
Advancement in tele surgery or long distance telerobotic surgery is an intriguing prospect achieve equitable reach of global surgical services. In realization of this dream there are multiple of challenges as to telesurgery establishment and operation in low-and middle-income countries (LMIC). As of current market status, telesurgery is costly and not practical for the austere settings in these countries. "Telesurgery for a truly global surgery" is a realisable dream for the fore coming future. Affordable robotic surgical platforms, assistance from manufacturing companies to establish robotic platforms, introduction of $5 \mathrm{G}$ networking technology, international collaboration to unify efforts in telesurgery, and secure networking framework for a hassle free telesurgery network; are few formidable suggestions for implementing telesurgery in a global scale.
\end{abstract}

Keywords: Telesurgery, Telerobotic surgery, Long distance telerobotic surgery, Robotic surgery, LIMIC, Global surgery, Telesurgery with $5 \mathrm{G}$

\section{INTRODUCTION}

The undoubted lesson learned from the COVID pandemic is that distance is no hinderance for efficient work execution. Telesurgery or long distance telerobotic assisted surgery, ponders on this concept where the surgery is performed by a surgeon on a patient that is physically distant. The concept of remote surgery was explored by NASA in the 70's to enable surgeons on the ground to perform surgery on astronauts in space. ${ }^{1}$ Refinement of robotic surgery technology and efficient high speed internet lead to the landmark first telesurgery to be performed in 2001 by professor Jacques Marescaux and team from IRCAD, France. Code named "operation Lindenberg", the first telesurgery was a cholecystectomy performed within 54 mins utilizing the computer assisted ZEUS robotic system and asynchronous transfer mode (ATM) internet technology. ${ }^{2}$

Ever since this historical milestone, telesurgery had an inequitable global growth. High income countries (HIC) are being the forerunners robotic surgery and telesurgery, while development of telesurgery in LMIC are hindered by high cost and in efficient networking system. ${ }^{3}$ In interest of achieving equitable surgical access for LMIC, telesurgery has a crucial and realistic role.

\section{BENEFITS OF TELESURGERY TO LMIC}

Based on Lancet commission on global surgery, 5 billion people from LMIC lack access to safe surgery and 143 million additional surgeries are required in these countries to save lives. ${ }^{4}$ The inequity to access to surgical services is due to financial constraint for travelling, lack of safe transportation or too far of a distance to hospitals. Telesurgery might just be the solution to this problem by mitigating distance between the surgeons and patients. ${ }^{5,6}$ Hence surgery can be done at the nearest local hospital with minimal distance travelled.

Shortage of trained surgeons is also one of the reasons for inequitable distribution of surgical service distribution. ${ }^{7}$ 
Telesurgery provides an excellent and robust platform for surgeons from all around the world to hand in a helping hand to regions in need without disrupting their duties at their native region. This also eliminates the risk and cost endured by surgeons travelling to remote areas. ${ }^{6,8}$

Complex surgical diseases are too often neglected in LMIC due to lack of multidisciplinary expertise. With telesurgery more than one surgeon can operate on a single patient at real-time simultaneously regardless of their location. Hence telesurgery encourages sharing of expertise between experts from all corners of the world with surgeons from LMIC. ${ }^{6,8}$

\section{PROBABLE SOLUTIONS TO CHALLENGES FACES IN DEVELOPING TELESURGERY IN LMIC}

A major challenge in implementing telesurgery in developing country will be the unaffordable cost imposed for initial establishment and operational of robot surgery platform. The cost is further burdened by the elevated price one has to pay for a secure and efficient network. It is estimated that purchasing a new robot surgery platform will cost approximately USD 1-2 million and maintenance per surgery will cost approximately USD $3000-5000 .^{5,9}$ In addition to that ATM network which is required for transmission of telesurgery will require around USD 100000 per year for operation cost. ${ }^{5}$ Hence the total operational cost for 100 surgeries performed will culminate to around USD 700000 to $800000 .^{5}$

These facts and figures will challenge the feasibility of telesurgery in LMIC. True globalisation of telesurgery can only be achieved once cost of the robot platform and networking reduces to an affordable rate for all countries. To achieve this, universal licencing for the robotic platform should be given to all manufacturer globally. As the competition for production increase, the market price will also reduce, hence increasing the demand for robotic surgery. The role of manufacturing companies to promote robotic surgery is also important. Companies should provide free training and simulation to surgeons in the developing countries. This reduces operational cost for training which is usually acquired as a fellowship to Europe or North America. Loans should be provided by companies to help LMIC to purchase robotic platforms. Besides that, encouraging sharing of robots between groups of hospital and proposed government subsidies to purchasing robotic surgery technology will further help in propagation of telesurgery in LMIC. The cost for networking can be reduced by implementing virtual private network (VPN) which reduces cost from USD 100000 to USD 100 per year. ${ }^{5,10}$ Besides that, 5G networking which is being introduced has a lower latency period and will have much reduced operational cost. ${ }^{11}$

Concerns for readiness of hospitals in LMIC with regards to hosting a robotic surgery platform in LMIC is a real challenge. Current robotic platform requires a well- spaced operation theatre with stable internet and electricity connection. To overcome lack of such infrastructure in austere environments, designing mobile robotic surgical units can mitigate problems in hosting traditional robotic surgery platforms. ${ }^{12}$

Secure and low-latency high speed network connection is important for telesurgery. ${ }^{10}$ Time-lag is a concern in telesurgery which can compromise patients' safety by imposing inaccuracies and increase unnecessary surgery time. $5 \mathrm{G}$ internet technology has a reduced latency period from the current 0.27 seconds to 0.01 seconds. ${ }^{11,13} 6$ hospitals in 6 different cities in China successfully performed spinal instrumental screwing on 12 patients in 2019 with utilisation of the novel 5G highspeed broadband. These 12 surgeries showed that $5 \mathrm{G}$ technology is safe and efficient platform for the future of telesurgery. ${ }^{14}$ Despite being in its infant stages in LMIC, $5 \mathrm{G}$ internet services are estimated to be fully implemented in developing countries in another 3-5 years' time.

The accuracy of robotic manipulation and video feedback is important for patients' safety. Security of data integrity is utmost important for a safe and successful telesurgery. ${ }^{10}$ Hence, if telesurgery becomes a global success in the future, one of the pragmatic operational challenges will be to overcome the multitude of cyber security treats. Various security framework has been proposed with accounts to authentication, authorization, confidentiality, integrity, anonymity and nonrepudiation services. ${ }^{15}$ These security frameworks will enable safe implementation of telesurgery networking worldwide.

Surgeons operating on remote patients who are divided by international borders are bound to face issues such as billing, insurance coverage, ethics and medical law. ${ }^{16}$ Formation of a single governing body inclusive of LMIC and HIC will mitigate some of these issues. Such an international collaboration will make telesurgery a more practical and realisable dream for the future.

\section{CONCLUSION}

A surgeon operating on a distant patient across international borders was once a futuristic and fictional dream has now been scientifically proven practical. Disseminating such technology as a solution to equitable and efficient global surgical services is a dream which we must realise and work towards. "Telesurgery for a truly global surgery" should be the ambitions of surgeons for the coming decade.

\section{ACKNOWLEDGEMENTS}

Author would like to thanks to engineers and surgeons participating in the development of telesurgery globally.

\author{
Funding: No funding sources \\ Conflict of interest: None declared
}


Ethical approval: The study was approved by the Institutional Ethics Committee

\section{REFERENCES}

1. Choi PJ, Oskouian RJ, Tubbs RS. Telesurgery : Past, Present, and Future. cureus. 2018;10(5):1-5.

2. Marescaux J, Leroy J, Gagner M, Rubino F, Mutter $D$, Vix $M$ et al. Transatlantic robot-assisted telesurgery. Nature. 2001;413(6854):379-80.

3. Telesurgery Market Existing and Future Insights in Growth. https://www.biospace.com/article/telesurgerymarket-existing-and-future-insights-in-growth/. 2021. Accessed on 10 Jan 2021.

4. Meara JG, Leather AJM, Hagander L, Alkire BC, Alonso N, Ameh EA et al. Global Surgery 2030: Evidence and solutions for achieving health, welfare, and economic development. Lancet. 2015;386(9993):569-624.

5. Cazac C, Radu G. Telesurgery--an efficient interdisciplinary approach used to improve the health care system. J Med Life. 2014;73(3):137-41.

6. Mohan A, Wara UU, Arshad Shaikh MT, Rahman RM, Zaidi ZA. Telesurgery and Robotics: An Improved and Efficient Era. Cureus. 2021;13(3).

7. Holmer H, Lantz A, Kunjumen T, Finlayson S, Hoyler M, Siyam A et al. Global distribution of surgeons, anaesthesiologists, and obstetricians. Lancet Glob Heal. 2015;3(S2):S9-11.

8. Feizi N, Tavakoli M, Patel RV, Atashzar SF. Robotics and AI for Teleoperation, Tele-Assessment, and Tele-Training for Surgery in the Era of COVID19: Existing Challenges, and Future Vision. Front Robot AI. 2021;8(4):1-9.

9. McBride K, Steffens D, Stanislaus C, Solomon M, Anderson T, Thanigasalam R et al. Detailed cost of robotic-assisted surgery in the Australian public health sector: from implementation to a multispecialty caseload. BMC Health Serv Res. 2021;21(1):1-8.

10. Avgousti S, Christoforou EG, Panayides AS, Voskarides S, Novales C, Nouaille L, et al. Medical telerobotic systems: Current status and future trends. Biomed Eng Online. 2016;15(1):1-44.

11. Zhang Q, Liu J, Zhao G. Towards 5G Enabled Tactile Robotic Telesurgery. 2018;1-7. Available at: http://arxiv.org/abs/1803.03586. Accessed on 10 Jan 2021.

12. Reichenbach M, Frederick T, Cubrich L, Bircher W, Bills N, Morien $\mathrm{M}$ et al. Telesurgery with miniature robots to leverage surgical expertise in distributed expeditionary environments. Mil Med. 2017;182:316-21.

13. Rassaf T, Multimorbidity R, Our IN, World A, Robertson $\mathrm{H}$, Nicholas $\mathrm{N}$ et al. $5 \mathrm{G}$ opens the future of telesurgery. Health Management org. 2018;18(4):4-6.

14. Tian W, Fan M, Zeng C, Liu Y, He D, Zhang Q. Telerobotic Spinal Surgery Based on 5G Network: The First 12 Cases. Neurospine. 2020;17(1):114-20.

15. Iqbal S, Farooq S, Shahzad K, Malik AW, Hamayun MM, Hasan O. SecureSurgiNET: A framework for ensuring security in telesurgery. Int J Distrib Sens Networks. 2019;15(9).

16. Valeriu A. Telesurgery and Robotic Surgery: Ethical and Legal Aspect. J Community Med Health Educ. 2015;05(03):4-5.

Cite this article as: Tamalvanan V. Foreseeable challenges in developing telesurgery for low income and middle income countries. Int Surg J 2021;8:32283230 . 